\title{
KELAYAKAN USAHA BUDIDAYA KOPI CIBULAO DALAM PROGRAM PENGELOLAAN HUTAN BERSAMA MASYARAKAT
}

\author{
Aceng Hidayat*, Arya Hadi Dharmawan**, dan Danang Pramudita* \\ ${ }^{1}$ Departemen Ekonomi Sumberdaya dan Lingkungan,Institut Pertanian Bogor* \\ Departemen Sains Komunikasi dan Pengembangan Masyarakat, Institut Pertanian Bogor**
}

\begin{abstract}
RINGKASAN
Program Pengelolaan Hutan Bersama Masyarakat (PHBM) merupakan suatu program pengelolaan sumberdaya hutan yang dilakukan bersama oleh Perum Perhutani dan Kelompok Tani Hutan (KTH) Cibulao Hijau berdasarkan Surat Keputusan Perhutani Nomor 682/KPTS/DIR/2009. Program ini dilakukan untuk mengatasi permasalahan pencurian tegakan pada kawasan hutan lindung disekitar Kampung Cibulao. KTH Cibulao Hijau memanfaatkan kawasan semak belukar di hutan menjadi lahan untuk ditanami tanaman kopi. Program PHBM ini memberikan manfaat kepada masyarakat Kampung Cibulao dalam aspek ekonomi, sosial dan lingkungan. Berdasarkan hasil persepsi masyarakat Cibulao terhadap manfaat program PHBM menggunakan skala likert menunjukan bahwa program ini telah memberikan perubahan yang lebih baik. Masyarakat juga telah merasakan manfaat baik secara langsung maupun tidak langsung walaupun manfaat yang dirasakan belum cukup merata kepada seluruh masyarakat cibulao. Budidaya kopi Cibulao yang dijalankan oleh KTH Cibulao Hijau menunjukan bahwa program ini layak secara finansial maupun ekonomi. Berdasarkan hasil analisis menggunakan metode Cost and Benefit Analysis dengan kriteria NPV, Net B/C, dan IRR menunjukan bahwa program PHBM ini secara finansial dan ekonomi layak untuk dijalankan.
\end{abstract}

Kata kunci: Cost and Benefit Analysi,s PHBM, Kelayakan, KTH Cibulao Hijau, Perum Perhutani

\section{PERNYATAAN KUNCI}

- Hutan yang terdapat disekitar Kampung Cibulao merupakan hutan produksi yang masuk dalam kawasan lindung sehingga fungsi hutan produksi berubah menjadi fungsi hutan lindung.

- Kebiasaan masyarakat Cibulao yang memanfaatkan tegakan hutan menjadi sumber kebutuhan sehari-hari mengakibatkan tekanan terhadap sebagian besar lahan di hutan akibat dari pencurian tegakan hutan yang dilakukan masyarakat.

- Program PHBM merupakan upaya dalam membangun kerjasama antara Perhutani dan KTH Cibulao Hijau dalam pengelolaan sumberdaya hutan. Pengelolaan ini diharapkan masyarakat lebih bertanggung jawab terhadap kelestarian hutan. Program ini bertujuan agar terwujudnya kelestarian dan keberlanjutan fungsi hutan serta peningkatan kesejahteraan masyarakat sekitar hutan. 
- Analisis persepsi masyarakat Cibulao dilakukan untuk mengidentifikasi manfaat yang telah dirasakan dari keberadaan program PHBM.

- Analisis kelayakan budidaya kopi Cibulao dilakukan untuk mengetahui kelayakan budidaya kopi yang sedang dijalankan. Hasil dari analisis ini akan memberikan informasi mengenai keberlanjutan program PHBM yang dilakukan di Kampung Cibulao.

\section{REKOMENDASI KEBIJAKAN}

- Perlunya dilakukan pembinaan dan penyuluhan oleh pihak perhutani kepada anggota KTH Cibulao Hijau serta melakukan pengembangan kegiatan dalam program PHBM yang lebih melibatkan masyarakat Cibulao secara keseluruhan sehingga manfaat yang dirasakan lebih merata.

- KTH Cibulao lebih baik mengusahakan kopi Cibulao dengan menjualnya dalam bentuk kemasan guna meningkatkan nilai jual kopi Cibulao. Selain itu, penjualan kopi Cibulao disarankan lebih luas cakupannya tidak hanya pada pemilik kafe-kafe kopi tetapi lebih melalui media online sehingga kopi Cibulao dapat lebih diketahui oleh masyarakat luas. Sehingga, kedepannya kopi Cibulao dapat dijadikan sebagai salah satu oleh-oleh yaitu kopi khas Bogor.

- Perlu adanya pendampingan yang lebih kontinyu dari pihak Perhutani dan Dinas terkait masyarakat Kampung Cibulao dalam melaksanakan sistem PHBM. Salah satu caranya adalah pemberian pengetahuan tentang PHBM oleh semua masyarakat Kampung Cibulao, perlu ditingkatkan melaluai sosialisasi, penyuluhan-penyuluhan dan pelatihan-pelatihan yang berkesinambungan.

\section{PENDAHULUAN}

Indonesia memiliki hamparan hutan yang luas yang didalamnya terdapat manfaat yang sangat beragam. Manfaat hutan yang ada meliputi fungsi konservasi, fungsi lindung, dan fungsi produksi untuk mencapai manfaat ekonomi, sosial, dan lingkungan yang seimbang serta bermanfaat bagi masyarakat. Keberadaan hutan sangat berkaitan dengan kelangsungan hidup masyarakat yang tinggal disekitar kawasan hutan. Masyarakat memanfaatkan hutan untuk memenuhi kebutuhan sehari-hari. Ketergantungan masyarakat terhadap hutan yang berada disekitarnya menyebabkan eksploitasi sehingga menimbulkan tekanan terhadap sumberdaya hutan. Data Badan Pusat Statistik (BPS) tahun 2016 menyatakan luas kawasan hutan Indonesia mencapai 126 juta hektare. Menurut Forest Watch Indonesia (2015) pada periode 2009-2013 Hutan Indonesia semakin mengalami laju penurunan sekitar 1,13 juta hektare setiap tahunnya. FWI (2014) dalam Potret Keadaan Hutan Indonesia 2009 -2013 menyimpulkan bahwa penyebab utama dari tingginya tingkat kerusakan hutan yang terjadi secara terus menerus di Indonesia adalah akibat dari lemahnya tata kelola hutan.

Perhutani merupakan badan usaha milik negara yang bertanggung jawab terhadap pengelolaan sumberdaya hutan yang menjamin fungsi dan manfaat hutan untuk kesejahteraan masyarakat dan kelestarian hutan. Pengelolaan hutan yang dilakukan oleh Perhutani dalam mengatasi permasalahan pengelolaan hutan yaitu melalui Pengelolaan Hutan Bersama Masyarakat (PHBM) 
berdasarkan Surat Keputusan Direksi Perhutani Nomor 682/KPTS/DIR/2009. PHBM merupakan upaya dalam membangun kerjasama antara masyarakat dan pemerintah dalam mengelola sumberdaya hutan. Melalui pengelolaan ini diharapkan masyarakat lebih bertanggung jawab terhadap kelestarian hutan. Program PHBM bertujuan agar terwujudnya kelestarian dan keberlanjutan fungsi hutan serta peningkatan kesejahteraan masyarakat sekitar hutan.

Hutan masyarakat Cibulao merupakan hutan produksi yang masuk dalam kawasan lindung sehingga fungsi hutan produksi berubah menjadi fungsi hutan lindung. Hutan ini mempunyai manfaat utama sebagai sistem penyangga kehidupan yaitu mengatur tata air, mencegah banjir, mengendalikan erosi, dan memelihara kesuburan tanah sehingga mampu memberikan perlindungan kepada kawasan sekitar agar terciptanya keberlanjutan sumberdaya alam dan jasa lingkungan bagi masyarakat. Kebiasaan masyarakat Cibulao yang memanfaatkan tegakan hutan menjadi sumber kebutuhan sehari-hari mengakibatkan sebagian besar lahan di hutan menjadi tidak berproduksi sehingga menjadi semak belukar. Keberadaan program PHBM memberikan manfaat kepada masyarakat dalam bidang ekonomi, sosial, dan lingkungan. Program PHBM yang dilakukan oleh KTH Cibulao Hijau yakni budidaya kopi dan wisata sepeda gunung. Mekanisme perjanjian kerjasama dalam program PHBM ini yaitu dengan sistem bagi hasil.

KTH Cibulao Hijau memanfaatkan lahan milik Perhutani menjadi lahan untuk ditanami tanaman kopi dengan konsep agroforestri. Luas kawasan hutan yang dikelola untuk program PHBM sampai tahun 2017 yaitu mencapai 31,5 hektar. Kopi merupakan tanaman yang cocok untuk dijadikan sebagai tanaman yang dibudidayakan untuk konservasi hutan. Tanaman kopi merupakan tanaman yang membutuhkan naungan agar bisa berkembang sehingga tegakan-tegakan yang terdapat di dalam hutan berfungsi sebagai naungan untuk tanaman kopi. Kopi juga dipilih karena komoditi ini memiliki nilai ekonomi yang tinggi dan strategis, baik untuk memberikan peningkatan pendapatan masyarakat serta meningkatan kesejahteraan masyarakat seperti di Desa Manggarai NTT jenis kopi Flores Robusta Manggarai.

Kopi Cibulao dikelola oleh beberapa masyarakat yang tergabung dalam Kelompok Tani Hutan (KTH) Cibulao Hijau dengan jumlah anggota sebanyak 25 orang. Kopi Cibulao merupakan kopi organik yang memiliki kualitas cukup tinggi. Pada tahun 2016 kopi robusta dari Kampung Cibulao meraih juara nasional dalam Kontes Kopi Spesialti Indonesia (KKSI) di Takengon Aceh. Perjanjian sharing profit pembagian hasil panen kopi yang disepakati oleh kedua belah pihak yaitu sebesar 75\% untuk KTH dan 25\% untuk Perhutani.

\section{SITUASI TERKINI}

Perjanjian kerjasama program pengelolaan hutan bersama masyarakat (PHBM) yang dilakukan oleh KTH Cibulao dan Perhutani dilaksanakan pada tahun 2009. Pada awalnya program ini hanya melibatkan 10 oarang yang diketuai oleh Bapak Jumpono namun pada tahun 2017 sudah berkembang menjadi 25 orang yang aktif tergabung dalam kelompok tani hutan. Kelompok Tani Hutan (KTH) Cibulao terdiri atas ketua, bendahara, sekretaris, bagian keamanan, bagian lapangan, bagian humas, bagian pembibitan 
Tabel 1 Produksi Kopi Cibulao per satuan hektar

\begin{tabular}{cc}
\hline Tahun & Produksi Kopi $(\mathrm{Kg} / \mathrm{ha} /$ tahun $)$ \\
\hline 2012 & 540 \\
2013 & 720 \\
2014 & 800 \\
2015 & 858 \\
2016 & 840 \\
\hline
\end{tabular}

Sumber : KTH Cibulao Hijau (2016)

dan bagian badan usaha. KTH Cibulao Hijau mengorganisir struktur organisasi dengan adanya spesialisasi kerja yang membantu berjalannya kegiatan operasional usaha secara lebih efektif dan efisien.

Pada tahun 2017 luas lahan kopi mencapai 31,5 hektar dengan jumlah tanaman kopi kurang lebih 50.000 pohon kopi. Lokasi dilaksanakannya program PHBM terletak di petak 7, 8E, 9 dan 11 yang termasuk ke dalam wilayah Resort Pemangku Hutan (RPH) Cipayung, Badan Kesatuan Pemangku Hutan (BKPH) Bogor, Perum Perhutani unit III Jabar. Produksi kopi cibulao yang telah dihasilkan dapat dilihat pada Tabel 1.

Program PHBM ini memanfaatkan ruang sela di kawasan hutan untuk menanam pohon kopi. Tanaman kopi membutuhkan naungan untuk berkembangnya untuk menghalangi sinar matahari langsung, idealnya tanaman kopi hanya membutuhkan 60 persen cahaya matahari langsung sehingga tegakan sangat berperan penting terhadap perkembangan tanaman kopi. Naungan yang digunakan oleh pohon kopi di Kampung Cibulao yaitu pohon endemik yang terdapat di dalam kawasan hutan lindung diantaranya yaitu pohon pasang, rasamala, puspa, kondang. Satu tegakan dapat menaungi 8 sampai 11 pohon kopi. Pada saat sebelum terlaksananya program PHBM, masyarakat sekitar hutan khususnya yang berada di Kampung Cibulao memanfaatkan tegakan hutan untuk keperluan kayu bakar, sehingga tegakan-tegakan yang berada di hutan jumlahnya semakin berkurang. Oleh karena itu, adanya program PHBM dapat mengurangi pencurian tegakan secara liar.

Pada tahun 2009-2013 KTH Cibulao Hijau menjalankan usahanya secara mandiri lalu pada tahun 2014 lembaga dari IPB yaitu Pusat Pengkajian Perencenaan dan Pengembangan Wilayah (P4W) datang untuk melakukan pembinaan kepada KTH Cibulao. P4W LPPM melakukan pembinaan dengan mendatangkan ahli kopi untuk memberikan pengetahuan kepada para anggota mengenai cara menanam kopi dan memanen kopi yang baik dan benar. Sejak saat itu kualitas dan produksi kopi Cibulao semakin meningkat, hingga pada tahun 2016 kopi Cibulao menjadi juara 1 nasional kopi spesialiti jenis robusta. Hal ini mengakibatkan harga kopi Cibulao semakin meningkat mencapai Rp 45000 per kilogram. KTH Cibulao Hijau menjual hasil panen kopinya dalam bentuk biji kopi mentah (green bean) Gambar 5 (c) adalah biji kopi yang sudah dikeringkan melalui proses penjemuran.

Penjualan kopi sampai saat ini langsung dijual kepada beberapa kafe kopi yang terdapat di Jakarta, Bogor dan Bandung. Biasanya para pemilik kafe datang secara langsung ke Cibulao untuk membeli kopi. KTH Cibulao Hijau harus memberikan sebagian hasil produksi kopi yang dihasilkan pihak Perhutani berdasarkan mekanisme bagi hasil yaitu sebesar 25 persen dari total produksi kopi setiap panen. 


\section{ANALISIS DAN ALTERNATIF SOLUSI PENANGANAN}

Penelitian ini dilakukan di Kampung Cibulao yang berlokasi di Desa Tugu Utara Kecamatan Cisarua Kabupaten Bogor. Pemilihan lokasi dilakukan secara sengaja (purposive) dengan alasan bahwa Kampung Cibulao, Desa Tugu Utara, Kecamatan Cisarua, Kabupaten Bogor melaksanakan program PHBM dengan Perhutani. Pengambilan data di lapangan dilakukan pada bulan Maret-April 2017. Jenis data yang digunakan adalah data primer dan data sekunder.

Dalam penelitian ini, peneliti menggunakan teknik pengambilan sampel non-probability sampling yaitu teknik sampling yang tidak memberikan kesempatan (peluang) pada setiap anggota populasi untuk dijadikan anggota sampel
(Riduwan, 2003). Metode pengambilan sampel untuk masyarakat Cibulao yang terlibat secara langsung dalam program PHBM dilakukan dengan menggunakan metode sensus jumlah responden sebanyak 25 orang yang terdiri anggota Kelompok Tani Hutan (KTH) Cibulao Hijau, sedangkan pengambilan sampel untuk masyarakat Cibulao yang tidak terlibat secara langsung dalam program PHBM menggunakan metode purposive sampling dengan jumlah responden sebanyak 33 orang.

Metode pengelolahan data yang digunakan dalam penelitian ini adalah metode kuantitatif dan kualitatif. Analisis data merupakan proses penyederhanaan data yang telah dikumpulkan oleh peneliti ke dalam bentuk yang lebih sederhana. Matriks keterkaitan antara tujuan penelitian, jenis data dan metode analisis data yang digunakan pada penelitian ini dapat dilihat pada Tabel 2 dibawah.

Tabel 2 Matriks Metode Analisis Data

\begin{tabular}{llll}
\hline No. & Tujuan Penelitian & \multicolumn{1}{c}{ Sumber Data } & \multicolumn{1}{c}{ Alat Analisis } \\
\hline 1. & $\begin{array}{l}\text { Mengidentifikasi persepsi masyarakat terhadap } \\
\text { terhadap manfaat program PHBM. }\end{array}$ & Data Primer & Skala Likert \\
2. & $\begin{array}{l}\text { Menganalisis kelayakan budidaya kopi yang } \\
\text { diusahakan KTH Cibula Hijau dalam program }\end{array}$ & $\begin{array}{l}\text { Data Primer dan } \\
\text { Sekunder }\end{array}$ & $\begin{array}{l}\text { Cost and Benefit Analysis } \\
\text { dengan Microsoft Excel } \\
\text { 2010 }\end{array}$ \\
$\begin{array}{l}\text { PHBM. } \\
\text { Mengestimasi tarif yang layak berdasarkan nilai }\end{array}$ & Data Primer dan & $\begin{array}{l}\text { Contingent Valuation Method } \\
\text { kesediaan membayar pengunjung untuk }\end{array}$ & Sekunder \\
menentukan potensi harga maksimum yang & & \\
masih bersedia dibayarkan untuk wisata Bike & & \\
Park yang dikelola KTH Cibulao Hijau & &
\end{tabular}

Tabel 3 Indikator Manfaat Program PHBM

\begin{tabular}{ll}
\hline Manfaat & \multicolumn{1}{c}{ Indikator } \\
\hline \multirow{3}{*}{ Bidang Ekonomi } & Meningkatkan pendapatan ekonomi rumah tangga masyarakat. \\
& Membuka lapangan pekerjaan \\
& Meningkatan kesejahteraan masyrakat. \\
\hline \multirow{3}{*}{ Bidang Sosial } & Meningkatkan keeratan dan gotong-royong antar masyarakat. \\
& Meningkatkan ilmu pengetahuan dan pengalaman baru \\
& Memberikan pemahaman tentang pentingnya menjaga hutan. \\
\hline \multirow{3}{*}{ Bidang Lingkungan } & Meningkatkan kelestarian hutan. \\
& Meningkatkan kualitas udara \\
& Tegakan Hutan menjadi terjaga \\
\hline
\end{tabular}

Sumber : Wildan (2015) dengan modifikasi 
Perhitungan persepsi masyarakat terhadap manfaat program PHBM menggunakan skala Likert merupakan alat untuk mengukur sikap, pendapat dan persepsi seorang atau sekelompok tentang kejadian atau gejala sosial (Riduwan 2003). Terdapat tiga indikator yang dianalisis yaitu manfaat program PHBM pada bidang ekonomi, bidang sosial dan bidang lingkungan.

Setiap indikator persepsi manfaat dari masingmasing bidang menghasilkan skor yang berasal dari nilai jawaban yang diberikan responden terhadap pernyataan yang diberikan dan dikalikan dengan jumlah responden yang memilih pada masing-masing jawaban. Kemudian, skor yang telah dihasilkan jumlahnya akan diakumulasikan lalu menghasilkan hasil akhir mengenai persepsi masyarakat terhadap manfaat program PHBM di Kampung Cibulao. Penilaian persepsi masyarakat terhadap manfaat program PHBM di Kampung Cibulao dibagi menjadi dua kelompok yaitu kelompok masyarakat yang terlibat dalam program PHBM dan kelompok masyarakat yang tidak terlibat dalam program PHBM.

Masyarakat yang terlibat dalam program PHBM merupakan anggota KTH Cibulao Hijau. Anggota KTH Cibulao Hijau secara langsung dapat merasakan manfaat dari keberadaan program PHBM ini. Analisis persepsi dilakukan untuk melihat seberapa besar manfaat yang telah dirasakan anggota KTH Cibulao Hijau dari

Tabel 4 Persepsi masyarakat yang terlibat program PHBM

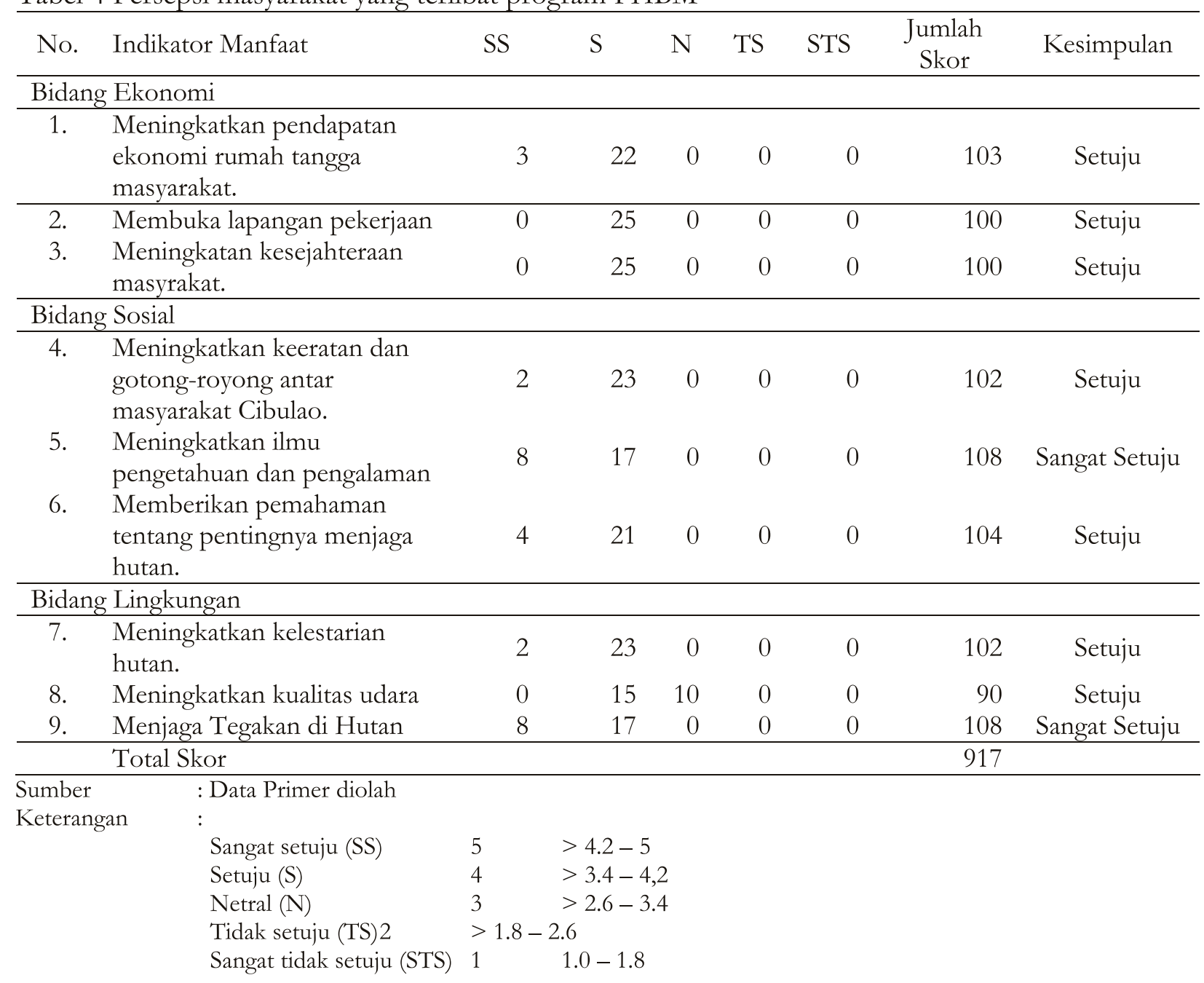


keberadaan program PHBM di Kampung Cibulao. Hasil wawancara kepada masyarakat yang terlibat dalam program PHBM menunjukan hasil yang diperoleh dengan rincian skor pada Tabel 4.

Hasil total skor yang diperoleh yaitu sebesar 917 sehingga apabila dilihat pada Gambar 2 garis kontinum persepsi masyarakat yang terlibat dalam program PHBM termasuk ke dalam kategori setuju. Hal ini dapat disimpulkan bahwa masyarakat yang terlibat dalam program PHBM merasakan manfaat dari adanya program PHBM secara keseluruhan dalam bidang ekonomi, sosial, dan lingkungan.

Masyarakat Kampung Cibulao yang tidak terlibat dalam program PHBM merupakan masyarakat yang tidak tergabung dalam KTH Cibulao Hijau. Masyarakat yang tidak terlibat merasakan beberapa manfaat dari keberadaan program PHBM baik secara langsung maupun tidak langsung. Analisis persepsi dilakukan untuk mengetahui manfaat apa yang telah dirasakan baik secara langsung maupun tidak langsung oleh masyarakat Kampung Cibulao yang tidak terlibat. Hasil wawancara kepada masyarakat yang tidak terlibat dalam program PHBM menunjukan hasil yang diperoleh dengan rincian skor pada Tabel 5 .

Hasil total skor yang diperoleh yaitu sebesar 953 sehingga apabila dilihat pada Gambar 2 garis kontinum persepsi masyarakat yang tidak terlibat dalam program PHBM termasuk ke dalam kategori Netral. Hal ini dapat disimpulkan bahwa masyarakat yang tidak terlibat dalam program PHBM belum merasakan manfaat program secara keseluruhan dalam bidang ekonomi, sosial, dan lingkungan. Program PHBM juga belum terlalu memberikan perubahan yang lebih baik dari sebelum program PHBM dilaksanakan bagi masyarakat yang tidak terlibat.

Kesimpulan akhir berdasarkan analisis persepsi masyarakat yang terlibat maupun yang tidak terlibat terhadap manfaat program PHBM menunjukan bahwa manfaat program PHBM telah memberikan manfaat secara langsung maupun tidak langsung serta memberikan perubahan yang lebih baik akan tetapi manfaat yang dirasakan belum merata kepada seluruh masyarakat Cibulao. Hal ini dikarenakan sebagian masyarakat masih awam tentang program PHBM sehingga mengakibatkan rendahnya partisipasi masyarakat Cibulao dalam program PHBM. Selain itu, keterbatasan lahan pengelolaan yang diizinkan oleh perhutani menyebabkan masyarakat tidak seluruhnya dapat memiliki lahan untuk diusahakan.

Penilaian kelayakan budidaya kopi Cibulao dilakukan secara finansial dan ekonomi. Penilaian kelayakan secara finansial dilakukan untuk mengetahui apakah usaha yang dilaksanakan menguntungkan bagi KTH sementara penilaian kelayakan secara ekonomi untuk mengetahui apakah usaha yang dilaksanakan menguntungkan

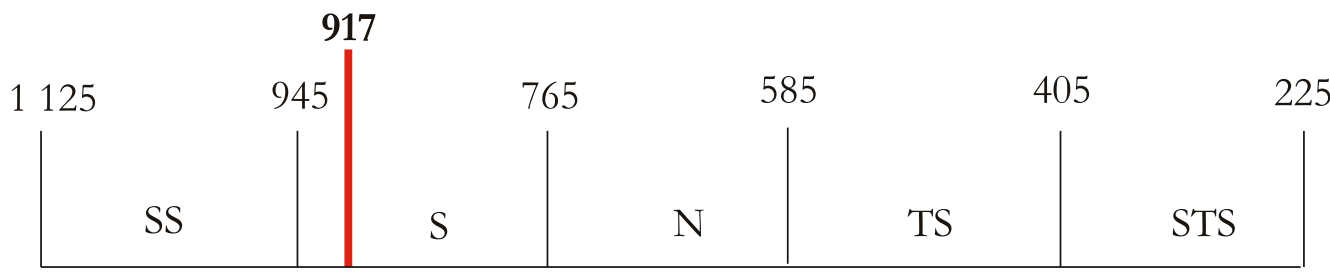

Gambar 1 Garis kontinum persepsi masyarkat yang terlibat program PHBM 
Tabel 5 Persepsi masyarakat yang tidak terlibat terhadap manfaat program PHBM

\begin{tabular}{|c|c|c|c|c|c|c|c|c|}
\hline No. & Indikator Manfaat & SS & S & $\mathrm{N}$ & TS & STS & $\begin{array}{c}\text { Jumlah } \\
\text { Skor }\end{array}$ & Kesimpulan \\
\hline \multicolumn{9}{|c|}{ Bidang Ekonomi } \\
\hline 1. & $\begin{array}{l}\text { Meningkatkan pendapatan } \\
\text { ekonomi rumah tangga } \\
\text { masyarakat. }\end{array}$ & 0 & 4 & 10 & 19 & 0 & 84 & Tidak Setuju \\
\hline 2. & $\begin{array}{l}\text { Membuka lapangan } \\
\text { pekerjaan }\end{array}$ & 0 & 6 & 4 & 23 & 0 & 82 & Tidak Setuju \\
\hline 3. & $\begin{array}{l}\text { Meningkatan } \\
\text { kesejahteraan masyrakat. }\end{array}$ & 0 & 2 & 7 & 24 & 0 & 77 & Tidak Setuju \\
\hline 4. & $\begin{array}{l}\text { Meningkatkan keeratan } \\
\text { dan gotong-royong antar } \\
\text { masyarakat Cibulao. }\end{array}$ & 0 & 10 & 23 & 0 & 0 & 109 & Netral \\
\hline 5. & $\begin{array}{l}\text { Meningkatkan ilmu } \\
\text { pengetahuan dan } \\
\text { pengalaman }\end{array}$ & 0 & 0 & 10 & 23 & 0 & 76 & Tidak Setuju \\
\hline 6. & $\begin{array}{l}\text { Memberikan pemahaman } \\
\text { tentang pentingnya } \\
\text { menjaga hutan. }\end{array}$ & 2 & 31 & 0 & 0 & 0 & 134 & Setuju \\
\hline \multicolumn{9}{|c|}{ Bidang Lingkungan } \\
\hline 7. & $\begin{array}{l}\text { Meningkatkan kelestarian } \\
\text { hutan. }\end{array}$ & 4 & 29 & 0 & 0 & 0 & 136 & Setuju \\
\hline 8. & $\begin{array}{l}\text { Meningkatkan kualitas } \\
\text { udara }\end{array}$ & 0 & 20 & 13 & 0 & 0 & 119 & Setuju \\
\hline 9. & $\begin{array}{l}\text { Menjaga Tegakan di } \\
\text { Hutan }\end{array}$ & 4 & 29 & 0 & 0 & 0 & 136 & Setuju \\
\hline & Total Skor & & & & & & 953 & \\
\hline
\end{tabular}

Sumber : Data Primer

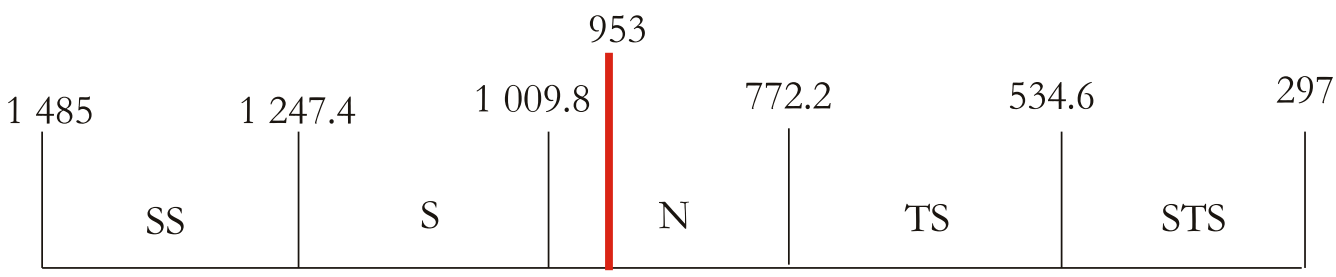

Gambar 2 Garis kontinum persepsi masyarkat yang tidak terlibat program PHBM

secara keseluruhan. Kelayakan ini menggunakan metode analisis biaya dan manfaat, dilakukan dengan mengelompokkan komponen biaya dan komponen manfaat yang terdapat dalam budidaya kopi yang dilakukan oleh KTH Cibulao Hijau dalam program PHBM. Komponen biaya adalah segala pengeluaran yang dikeluarkan oleh KTH Cibulao Hijau yang terdiri biaya investasi dan biaya operasional. Komponen manfaat adalah segala bentuk pemasukan yang diperoleh dari budidaya kopi KTH Cibulao Hijau dalam menjalankan program PHBM.

Menentukan layak atau tidaknya suatu usaha dinilai berdasarkan beberapa kriteria kelayakan investasi. Kriteria kelayakan investasi yang digunakan dalam penelitian ini terdiri dari Net Present Value (NPV), Internal Rate of Return (IRR), dan Net Benefit and Cost Ratio (Net B/C).

\section{NetPresent Value (NPV)}

Suatu bisnis dapat dikatakan layak jika jumlah seluruh manfaat yang diterimanya melebihi biaya yang dikeluarkan. Selisih antara manfaat dan biaya 
disebut dengan manfaat bersih. Net Present Value atau nilai kini manfaat bersih adalah selisih antara total present value manfaat dengan total present value biaya atau jumlah present value dari manfaat bersih tambahan selama umur bisnis. Suatu bisnis dinyatakan layak jika NPV lebih besar dari nol yang artinya bisnis menguntungkan atau memberikan manfaat. Apabila suatu bisnis mempunyai NPV lebih kecil dari nol maka bisnis tersebut tidak layak untuk dijalankan (Sinaga 2009). Rumus perhitungan NPV adalah sebagai berikut:

$$
N P V=\sum_{t=0}^{n} \frac{B t-C t}{(1+i)^{t}}
$$

Bt : Manfaat yang diperoleh setiap tahun

Ct : Biaya yang dikeluarkan setiap tahun

$\mathrm{N}$ : Jumlah tahun

i :Tingkat Discount Rate

\section{Net Benefit and Cost Ratio (Net B/C)}

Net Benefit and Cost Ratio (Net B/C) merupakan perbandingan antara manfaat bersih yang bernilai positif dengan manfaat bersih yang bernilai negatif. Suatu bisnis atau kegiatan investasi dapat dikatakan layak bila Net B/C lebih besar dari satu dan dikatakan tidak layak bila Net B/C lebih kecil dari satu (Sinaga 2009). Adapun rumus perhitungan $\mathrm{Net} B / \mathrm{C}$ yaitu:

\section{Keterangan:}

$$
\text { Net } B / C=\frac{\sum_{t=0}^{n} \frac{(B t-C t)}{(1+i)^{t}}(\text { positif })}{\sum_{t=0}^{n} \frac{(B t-C t)}{(1+i)^{t}}(\text { negatif })}
$$

Bt : manfaatyang diperoleh setiap tahun

$\mathrm{Ct}$ : biaya yang dikeluarkan setiap tahun

n : jumlah tahun

i : tingkat Discount Rate

\section{Internal Rate of Return(IRR)}

Kelayakan bisnis juga dinilai dari seberapa besar pengembalian bisnis terhadap investasi yang ditanamkan yang ditunjukkan dengan mengukur besaran Internal Rate of Return (IRR). IRR adalah tingkat discount rate yang menghasilkan NPV sama dengan nol. Besaran yang dihasilkan dari perhitungan ini adalah dalam satuan presentase. Sebuah bisnis layak apabila IRR lebih besar dari tingkat suku bunga yang berlaku (Sinaga 2009). Rumus IRR yaitu :

$$
I R R=i_{1}+\frac{N P V_{1}}{N P V_{1}-N P V_{2}} x\left(i_{2}-i_{1}\right)
$$

$\mathrm{i}_{1} \quad$ : Discount rate yang menghasilkan NPV positif $\mathrm{i}_{2}$ : Discount rate yang menghasilkan NPV negatif $\mathrm{NPV}_{1}:$ NPV yang bernilai positif $\mathrm{NPV}_{2}: \mathrm{NPV}$ yang bernilai negatif

Kelayakan investasi program PHBM yang dilakukan oleh KTH Cibulao Hijau dalam mengusahakan tanaman kopi di lahan milik perhutani secara finansial menggunakan kriteria Net Present Value (NPV), Net Benefit Cost Ratio (Net B/C), dan Internal Rate of Return (IRR) dapat dilihat pada Tabel 6 .

Nilai Net Present Value (NPV) didapat dari menjumlahkan nilai present value (PV) dari tahun ke0 sampai tahun ke-15. Setelah dilakukan penjumlahan, didapatkan hasil NPV sebesar 90.009.888. Hal ini menunjukkan bahwa program ini akan memberikan manfaat bersih sebesar 90.009.888. Berdasarkan kriteria NPV, suatu proyek atau usaha layak untuk dijalankan apabila memiliki nilai NPV lebih besar daripada nol. Kesimpulan menurut kriteria tersebut, budidaya kopi dalam program PHBM layak untuk dilaksanakan secara finansial.

Nilai Net Benefit Cost Ratio (Net B/C) didapat dengan membandingkan antara pemasukan dan pengeluaran. Setelah dilakukan perbandingan antara pemasukan dan pengeluaran, didapatkan hasil Net B/C sebesar 2,31. Hal ini berarti setiap 
Tabel 6 Kriteria Kelayakan secara Finansial

\begin{tabular}{llrl}
\hline No. & Kriteria Kelayakan Investasi & Besaran & Kesimpulan \\
\hline 1. & Net Present Value (NPV) & 92.009 .888 & Layak \\
2. & Net Benefit Cost Ratio (Net B/C) & 2,31 & Layak \\
3. & Internal Rate Return (IRR) & $12 \%$ & Layak \\
\hline
\end{tabular}

Rp 1 yang dikeluarkan dalam program PHBM akan menghasilkan tambahan manfaat bersih sebesar Rp 2,31. Berdasarkan kriteria Net B/C, suatu proyek atau usaha layak untuk dijalankan apabila memiliki nilai Net B/C lebih besar daripada satu. Kesimpulan menurut kriteria tersebut, budidaya kopi dalam program PHBM layak untuk dilaksanakan secara finansial.

Setelah dilakukan perhitungan, didapatkan hasil IRR sebesar 12 persen. Hal ini menunjukkan bahwa program PHBM mampu memberikan tingkat pengembalian modal sebesar 12 persen. Berdasarkan kriteria IRR, suatu proyek atau usaha layak untuk dijalankan apabila memiliki nilai IRR lebih besar daripada nilai discount rate atau suku bunganya. Menurut kriteria tersebut, program PHBM yang dilakukan oleh KTH Cibulao Hijau layak untuk dilaksanakan secara finansial.

Pada analisis ekonomi kelayakan program PHBM yang dilakukan oleh KTH Cibulao Hijau dalam mengusahakan tanaman kopi di lahan milik perhutani secara ekonomi menggunakan kriteria Net Present Value (NPV), Net Benefit Cost Ratio (Net B/C), dan Internal Rate of Return (IRR) adalah sebagamana pada Tabel 7:

Nilai Net Present Value (NPV) didapat dari menjumlahkan nilai present value (PV) dari tahun ke-0 sampai tahun ke-15. Setelah dilakukan penjumlahan, didapatkan hasil NPV sebesar 196
672 707. Hal ini menunjukkan bahwa program ini akan memberikan manfaat bersih kepada masyarakat dan lingkungan sebesar 196672707. Berdasarkan kriteria NPV, suatu proyek atau usaha layak untuk dijalankan apabila memiliki nilai NPV lebih besar daripada nol. Kesimpulan menurut kriteria tersebut, program PHBM layak untuk dilaksanakan. Berdasarkan kriteria NPV, program PHBM telah memberikan manfaat kepada masyarakat dan lingkungan.

\section{Nilai Net Benefit Cost Ratio (Net B/C)} didapat dengan membandingkan antara pemasukan dan pengeluaran. Setelah dilakukan perbandingan antara pemasukan dan pengeluaran, didapatkan hasil Net B/C sebesar 4.19. Hal ini berarti setiap Rp 1 yang dikeluarkan dalam program PHBM akan menghasilkan tambahan manfaat bersih kepada masyarakat dan lingkungan sebesar Rp 4.19. Berdasarkan kriteria Net B/C, suatu proyek atau usaha layak untuk dijalankan apabila memiliki nilai Net B/C lebih besar daripada satu. Kesimpulan menurut kriteria tersebut, program PHBM layak untuk dilaksanakan secara ekonomi.

Setelah dilakukan perhitungan, didapatkan hasil nilai IRR sebesar 23 persen. Hal ini menunjukkan bahwa program PHBM mampu memberikan tingkat pengembalian modal sebesar 23 persen. Berdasarkan kriteria IRR, suatu proyek

Tabel 7 Kriteria Kelayakan secara Ekonomi

\begin{tabular}{llrr}
\hline No. & Kriteria Kelayakan Investasi & \multicolumn{1}{c}{ Besaran } & Kesimpulan \\
\hline 1. & Net Present Value (NPV) & 196672707 (?) & Layak \\
2. & Net Benefit Cost Ratio (Net B/C) & 4.19 & Layak \\
3. & Internal Rate Return (IRR) & $23 \%$ & Layak \\
\hline
\end{tabular}


atau usaha layak untuk dijalankan apabila memiliki

nilai IRR lebih besar dari pada nilai discount rate atau suku bunganya. Menurut kriteria tersebut, program PHBM yang dilakukan oleh KTH Cibulao Hijau layak untuk dilaksanakan secara ekonomi.

\section{REFERENSI}

Affianto, A., Djatmiko, WA., Hermawan, T.T., Riyanto, S. 2005. Analisis Biaya dan Pendapatan Dalam Pengelolaan PHBM: Sebuah Panduan Perhitungan Bagi-Hasil. Bogor (ID): Pustaka Latin.

Aklimawati, et al. 2014. Karakteristik Mutu dan Agribisnis Kopi Robusta di Lereng Gunung Tambora, Sumbawa. Pelita Perkebunan. 30(2) 159-180.

Arief, A. 2001. Hutan dan Kehutanan. Yogyakarta (ID): Kansius.

Budiarti, S. 2011. Persepsi dan Partisipasi Masyarakat Desa Sekitar Hutan Terhadap Sistem PHBM di Perum Perhutani [skripsi]. Bogor (ID): Institut Pertanian Bogor.

Busch J, et al. 2012. Structuring Economic Incentives to Reduce Emissions From Deforestation within Indonesia, Proceedings of the National Academy of Science 109:1062-1067.
[BPS] Badan Pusat Statistik. 2016. Luas Kawasan Hutan Indonesia. Jakarta (ID): Badan Pusat Stastik.

[FWI] Forest Watch Indonesia. 2014. Potret Keadaan Hutan Indonesia 2009-2013. Bogor (ID): Forest Watch Indonesia . 2015. Intip

Hutan. Bogor (ID): Forest Watch Indonesia.

Riduwan. 2003. Dasar-dasar Statistik. Bandung (ID): PT. Alfabeta.

Sinaga, D. 2009. Studi Kelayakan Bisnis dalam Ekonomi Global. Jakarta (ID): Mitra Wacana Media.

Surat Keputusan (SK) direksi perhutani No. 682 / KPTS / DIR/2009 tentang Pengelolaan Hutan Bersama Masyarakat.

Wildan, M. 2015. Analisis Kelayakan Dan Efektivitas Program Gerakan Menabung Pohon Melalui Pengelolaan Hutan Bersama Masyarakat [Skripsi]. Bogor (ID). Institut Pertanian Bogor.

Walpole, R.E. 1992. Pengantar Statistika. Jakarta (ID): Gramedia Pustaka Utama.

Wisman, I.N. 2010. Kelayakan Usaha Agroforestri Mahoni (Swietenia macrophylla King) dan Kopi (Coffea spp) dengan Sistesm Bagi Hasil di BKPH Candiroto, KPH Kedu Utara Perum Perhutani Unit I Jawa Tengah [Skripsi]. Bogor (ID). Institut Pertanian Bogor. 